\title{
What is a reference?
}

\author{
Yoram Reich $^{1}$
}

Published online: 14 September 2017

(C) Springer-Verlag London Ltd. 2017

\section{The motivation}

I just came back from two conferences, ASME IDETC17 in Cleveland and ICED17 in Vancouver. In the latter, several editorial boards meetings of journals related to design were held, including that of Research in Engineering Design. A recurring topic in these meetings was the inadequate state of referencing and conducting literature review in the engineering design community. This has impact on several aspects such as the status of journals as determined by their impact factor, which directly depends on citations. It also may distort the perception of the state of the art if key papers are ignored and others referenced. Many editorial board members and editors thought it would be a good idea to create a community effort to improve the situation.

Part of my work as editor is to reflect on different topics such as quality of referencing on a regular basis. It occurred to me that a fundamental concept that underlies the problem, that remains to be reformulated, is the term "reference." I decided as part of initiating the aforementioned community

Yoram Reich

yoram@eng.tau.ac.il

1 Tel Aviv University, Tel Aviv, Israel effort, to devote an editorial to the question: "what is a reference?"1

(1) How would you go about addressing this question? Take a moment to think about it. Try to recall when was the last time you thought about this question? ${ }^{2}$

As a design researcher, my personal bias, and following my Principle of Reflexive Practice (PRP; Reich 2017), ${ }^{3}$ is to address any question as a design problem. ${ }^{4}$ This should not be a surprise as a reference is not born by nature but is a man-made object; it has been designed. Continuing with the PRP, I will further use a particular design framework to direct me in the process.

(2) Pause again. How would you design a reference?

My personal preference is to use the PSI framework (Reich and Subrahmanian 2015, 2017) ${ }^{5}$ to organize the design process. PSI tells me that carrying out this design, I have to formulate the problem and address it with others who may be affected by the design; these would be authors,

\footnotetext{
${ }^{1}$ Many books and also editorials have been written about literature review. I have not seen one from a design perspective and most do not mention the social aspect of the activity. In any case, periodic reflection is necessary.

2 Try to actually use the questions in this editorial as an exercise and not as a stylistic way for me to introduce the next topic.

3 This is the most recent and expanded version of this concept with recent supporting evidence.

${ }^{4}$ This is my answer to question (1); very simple. Compare it to your own answer.

5 I selected these references because they provide the information about the PSI. Unfortunately, at this stage, there is no journal publication that would be more comprehensive.
} 
Table 1 1st PSI diagram - in meetings at ICED, people involved in managing journals reflected on the status of referencing and agreed that better quality referencing should be one vision of the community

\begin{tabular}{lll}
\hline What & Who & How \\
\hline We need much better quality referencing & Self-reflective researchers involved in editorial practices & Face-to-face discussions \\
\hline
\end{tabular}

Table 2 2nd PSI diagram - the implementation or reflection level attempts to implement the strategic goal by changing the practices of an existing community-a very tough problem

\begin{tabular}{lll}
\hline What & Who & How \\
\hline Designing quality and acceptable referencing & Me, reviewers, authors, others to be determined & $\begin{array}{c}\text { PSI, editorial and community process to be } \\
\text { determined }\end{array}$ \\
\hline
\end{tabular}

Table 3 3rd PSI diagram

\begin{tabular}{lll}
\hline What & Who & How \\
\hline Designing a reference & Me & Traditional process, C-K, morphological chart, ASIT \\
\hline
\end{tabular}

reviewers, and others. As this cannot be done now, I am using the editorial as a way to launch a discussion where the community effort discussed before would ultimately resolve the question. Let us capture the process so far by PSI diagrams. The 1st diagram (Table 1) captures the discussions in ICED17. The 2nd diagram (Table 2) captures this editorial and the anticipated future community discussion.

A framework helps us place our activity in the right context, giving it better shape. Let us remember this as we proceed with this editorial.

Let me start the design knowing that this is just a prompt for inviting others to participate in the reflection, subsequent design, and later use of references as agreed upon collectively. This is reflected in the 3rd diagram (Table 3).

\section{(3) How would you actually proceed in the design?}

We need some process to design. We should have agreed upon it in the previous step (2nd diagram) but given that that step was not really fully exercised, we are jumping to the present and I have to pick my design process. I'll start with a classic process of framing the problem, proposing conceptual solutions, adding details until they are good enough to be used. I'll only simulate the process as a first iteration; a prototype and leave the rest for subsequent community efforts. Even this prototype may start serving as a guideline for authors and reviewers to further gather insight about the problem.

(4) What might be the objectives of a good reference? What is the purpose of a reference?
Let us consider several answers:

1. A specific claim is made in the paper which is central to the argument of the paper (e.g., "The initial stages of design determine about $70-80 \%$ of product quality and cost" which will hence forth referred to as IISP (importance of initial stages principle); this principle may be used to argue for developing a good concept for design tools). A reference is needed to support this claim even if we think it is roughly true.

2. A general claim is made in the paper that is not central to the main argument (e.g., "Additive manufacturing is changing the industry;" the analysis developed in this study can also support the additive manufacturing process). You wish to provide a reference that will present additional background material to readers.

3. A statement is copied verbatim from another source. It should be quoted and the exact reference must be provided to avoid plagiarism.

It is safe to say that there are additional variations on these objectives such as:

4. Providing additional material for specific claim that is not central to the argument. 
5. Providing direct support for a general claim that is central to the argument.

By enumeration, we can find all the combinations of $\{$ specific, general $\} \times\{$ central, ,otcentral $\} \times\{$ directsupport, additionalmaterial $\}$ (generalized and denoted by specificity $\times$ centrality $\times$ informativity).

We may even use an approach such as C-K theory (Hatchuel and Weil 2009) ${ }^{6}$ or another creativity method to add more values or more attributes. An easy additional value for the informativity is contradicting evidence. While this value could be cast as supporting evidence; keeping it separate will remind us to make sure we also consider it when we conduct literature review and not just when looking for supporting evidence. Another value is recognizing originator. Especially in science, it is important to acknowledge the first one who invented something, if it is known.

The reason to carry out this exercise is because the particular objective of the reference may lead to designing a different type of reference. To illustrate, objective 1 requires a good quality reference while objective 2 could be left with perhaps a reasonable quality reference. We may be content with reasonable quality because as in design, our literature review has resource constraints. Quality is a general attribute. Let us examine what properties of reference may influence it.

\section{Properties of references}

\subsection{Source of references-"not all references are born equal"}

An internal document or a working paper and a journal paper do not have the same status. Referencing a journal paper is better. We rely on the journal reviewing process to claim that the journal paper has better chances to be good. In doing so, we also have to gage the type of journal as not all journals are the same. Similarly, a journal paper would be better than a conference paper. It will definitely be so when the journal paper is an expanded version of the conference paper, assuming that the authors have incorporated comments from the conference presentation and further from the journal review process. (Always check for a journal version of a conference paper to read and cite it.)

\footnotetext{
${ }^{6}$ I had at least three options to choose for this reference: the original conference paper (Hatchuel and Weil 2003), the journal paper (Hatchuel and Weil 2009), and a recent book (Le Masson et al. 2017). I selected the journal because it provides the description of the theory with examples and is accessible. The book is much more elaborate but may be less accessible and would require more time to understand the basics of $\mathrm{C}-\mathrm{K}$.
}

Let us consider sources of the same type, for example, journals. Different journals have different reputation. This reputation is usually ascribed to papers published in them, but clearly, not all papers in the same journal are equally good. As an editor, I can easily observe this from the variability in the assessments that reviewers give to different papers. This means that ultimately, we need to exercise our own judgement given all the information.

With the current surge in new journal appearances, one has to be much more careful in judging the reputation of a journal or a paper. There are journals without a review process that would be considered of less quality than many conferences. Again, a general heuristic may be that older journals have a better established review process than new ones, but as always, there are exceptions.

\subsection{Time of reference appearance-publication date of references ${ }^{7}$}

We are accustomed to think that newer is better, an improved version of the past. The story of science is that new work rests on old, improves it, and references it. This would allow us to reference the new, rather than the old. But is it always the case? Consider a product developed in the US and then a new version is sold in Europe; would it be considered better? Not necessarily if regulations or the market are different. The same works for references; context matters. Consider again the aforementioned IISP. What is the source of this statement and does it apply today? I answer the first question in Sect. 3 and for now only say that it was based on studies of physical products in specific places. Would it apply to other places such as Japan or would it apply to software or mechatronic products with significant software components? If the context of the original studies escaped us, aren't we simply overgeneralizing? Another error we make in referencing new material is that we cite references without a trail of evidence but that simply state the same claim we want to propose. Often it is easier to find such documents rather than do the hard work. Overgeneralizations of claims or citing mere statements are two classic mistakes of referencing.

The answer to the question whether to cite old or new is therefore complicated: "it depends". If you want to mention the originator, find the oldest source; if you need the original data or other particular data, use the source that "owns" it. If you want to use updated information, use a good review or a paper that includes a good analysis of the literature; use the best review available. What's important is the quality of the reference and not its time of appearance per se even though

\footnotetext{
7 In published work, publication date is important but there could be other ways to judge precedence as in Patents where submission date is governing. This demonstrates that even such simple property of a reference could be defined and agreed upon by a community.
} 
unfortunately only recent papers are counted in the evaluation of journals through their impact factor.

\subsection{Accessibility of references}

The accessibility of references is not directly related to quality but to the social process of reviewing and subsequent reading of papers. An accessible reference allows readers to actually read it and make their own judgement about the study's claims. A reference that is less accessible (including in a language different than English), may render such self judgement difficult. I am not suggesting excluding foreign language references; I am only adding another property of references to complicate the task of referencing.

Consequently, open source or regular journal papers that one may find in common libraries may be good sources. New journals, beyond their quality issue, may also suffer from little accessibility. Internal reports or proceedings without electronic version may be hard to get.

In design, usability is critical, similarly in referencing, usability means accessibility and verifiability.

\subsection{References and their authors}

We tend to refer to known researchers rather than quality work. We tend to refer to highly cited work when it may no longer be the newest, best quality, or most comprehensive. This phenomenon is a reflection of the scale-free network (Barabási 2009) ${ }^{8}$ nature of citation networks (Redner 1998). ${ }^{9}$ In such networks, new nodes tend to be attached to nodes with many citations rather than those with few. Nevertheless, choosing the most famous author or reference may not be the best choice.

For example, a highly cited paper is criticized by a new study and an author wishing to continue the line of research of the highly cited paper either is not aware or worse, ignores, the latter critical reference. In any of these cases, this omission reflects on the scholarship of the author. To

\footnotetext{
${ }^{8}$ I selected this reference because it is by the originator of the concept and provides a 10-year reflection on the subject which may be better introduction to the topic than the original paper.

9 This reference is mentioned in (Barabási 2009) and has attracted so many citations to prove its point. I finally selected it without much additional search as it provides evidence that my claim has merit. Nevertheless, when I started the literature search, the first citation was (Wang et al. 2010). It is a conference paper by less known people with only one citation in a dissertation. It seemed a less quality citation. But upon closer inspection, this paper provides also interesting analysis that considers also the dynamics of citation data on the formation of the citation network. It is a better reference?
}

give one example, consider Simon's the Sciences of the Artificial (Simon 1996). While the book has its merit, design as understood today is different from the one described by Simon. ${ }^{10}$

This example of Simon relates also to references and different schools of thought in design, what elsewhere I referred to as design religions (Reich 2010b). This is elaborated in the next subsection.

\subsection{Referencing and design schools of thought}

How do design schools of thought influence referencing? Let's consider an example of two such schools: decision theory and pragmatic engineering methods. They are epitomized in a debate that took place in Research in Engineering Design in 2010 (Frey et al. 2009, 2010; Hazelrigg 2010; Reich 2010a) ${ }^{11}$ but could be found elsewhere. ${ }^{12}$ The point of the debate is not necessarily to determine who is right but to maintain consistency in reasoning. It is easy to find papers in both schools not mentioning the other school even when it is appropriate.

Another example is the debate between the value of case studies and lab experiments, especially experiments that address a single aspect of design. These experiments most often use various methods from cognitive and social sciences to collect the required data. In this context, it is instrumental to mention Newell's (1973) paper titled "You can't play 20 questions with nature and win" to claim that complex phenomena cannot be broken into tiny questions whose answer compose the complete phenomena. Newell designed his approach to be based on a comprehensive cognitive architecture called Soar that was supposed to give answers (Laird et al. 1987). Are authors today familiar with this debate? ${ }^{13}$ And there may be other debates that enrich our work and provide opportunities for further work if we noted them.

\footnotetext{
${ }^{10}$ I leave to the reader as an exercise to find at least 5 credible references arguing against Simon's view of design.

${ }^{11}$ I selected to explain this topic with these references because I have personal experience with the process and it was easier to use them and this topic rather than find another debate in engineering design. We are not used to conduct open debates about different topics. Can you name 3 debates you are familiar with in engineering design and mention scholarly references that discuss them?

12 Can you find 2 other references that discuss these schools and the controversy among them? Could you identify another reference in this editorial that comments on this controversy?

13 This is not a devious question. It may not be easy to know about such debates if you do not search for them. My acquaintance with them comes from personal experience having been the editor of the journal in the first example and working in Newell's Soar group at Carnegie Mellon University in the 1980's.
} 
As a community, we should encourage open debates on important topics. It is certainly within the journal mission to foster them.

\section{Building an argument using references}

Let us take a concrete example of referencing. In design, we say that prototyping works by allowing us intimate access to knowledge at the beginning of the process which is so important. Let us prototype; let us explore precisely this point as an exercise on referencing. Let us find a reference that supports the IISP.

(5) How would you search for this reference?

A simple search on keywords from the sentence leads us to (Bragança et al. 2014) in a journal that is 17 years old, indexed by many databases but not ISI; therefore, it does not have the traditional impact factor.

The paper states a variation of the IISP: "If a project is well planned and sustainable criteria are included in its early approach, the possibility to reduce negative impacts is greater and the cost of criteria implementation is greatly reduced."

The paper includes a figure to illustrate the claim but it has a conceptual error; it does not reflect the impact of early decisions. The figure is taken from a referenced paper (Kohler and Moffatt 2003); which is a publication of the UN that looks like a journal that has been discontinued in 2004. The figure appears exactly with the same error in this paper without any reference and no supporting data.

\section{(6) What is your analysis of these references?}

How did I cope with question (5)? In a conference publication (Reich 2008), ${ }^{14}$ I built an argument for supporting conceptual design that used a qualitative soft version of the IISP as its basis that states: "It is well accepted that the initial development stages determine the majority of the quality and cost of a product (Pahl and Beitz 1996; Ullman 2003)". What I was missing in my referencing and analysis, if I wanted to be more accurate, is to refer to contradicting opinions (Barton et al. 2001; Ulrich and Pearson 1993) ${ }^{15}$ that build an argument against this received view.

\footnotetext{
${ }^{14} \mathrm{I}$ am using my own omission here to demonstrate that no one is perfect. The goal is constant improvement in carrying out this important task.

15 I contend that (Ulrich and Pearson's (1993) study is ill posed. For example, after generating the design, some manufacturing options make no sense and could be eliminated or not considered a priori, leading to much less manufacturing variation. In addition, the design variation is considerably reduced in the study because the study analyzed complete designs and not the set of candidate designs originally created by developers.
}

It is instrumental to further explore the case of the IISP. Ullman (2003) mentions internal data from Ford without a reference. He cites (Ulrich and Pearson 1993) to support part of the IISP although their final conclusion is that the numbers in the IISP are unsupported. He also mentions some Xerox data without a reference. Altogether, Ullman does not offer substantial publicly accessible information sources in support of the IISP.

While searching for additional support for the IISP, I found additional references. Saravi et al. (2008) cite Ullman (2003) and then Corbett (1986) and Mileham et al. (1993). Saravi et al. interpretation of Corbett is wrong and their addition of Mileham et al. as a reference is redundant because the latter refer only to Corbett (and they do it correctly) as their support of the IISP.

Corbett (1986) does not really deal with the IISP but mentions a study by Rolls Royce (Symon and Dangerfield 1980). This paper seems to be the only one accessible with firsthand information.

One piece of information mentioned is an analysis of 2000 drawings of components that were analyzed to assess how much of their unnecessary cost could be reduced and how. The result was:

Design schemes (presumably conceptual design) $-50 \%$.

Detailed drawings-30\%.

Production engineering-20\%.

This however does not say how much of the cost is determined in the different stages. Nevertheless, the argument made was that this demonstrates the criticality of the initial stages. The authors further note that this is an example similar to Pareto principle in which, in the first $10 \%$ of the project time, $90 \%$ commitment is made on cost. How is it related to the IISP? Unclear since it is unknown how long do the initial design stages last in the authors data.

Another such referencing sequence starts with (Hsu and Woon 1998) who cite Lotter's (1986) study; but Lotter, in turn, does not mention his study but bases the argument on a German PhD thesis (Gairola 1981). In the short period of writing this editorial I was not able to access this German study. We see that the above sequences of referencing could be improved; presently, they lead to conclusions that beg for additional support.

Let us reflect upon the exercise we just went through. (1) The way I found the references mentioned in this exercise is by a simple Google search with the keywords from the IISP phrase. When I found a reference, I looked for the supporting evidence and drilled down until I came to the actual data. The Rolls Royce reference was one such starting point. From there, I searched for its citations and found other studies that reference it. I did not find them in the first search including the contradicting references. Such drilling down 
and tracing back up is a good strategy for finding references. (2) A simple study of the literature reveals that referencing practice could be much improved. It may be time consuming but also presents new opportunities. For example, I was not aware of the Rolls Royce case study and the additional information it contains provided me with support for the work on PSI framework. (3) Careful referencing could lead to potential research topics such as finding concrete support for the IISP or its revision to account for new data. (4) The above analysis notwithstanding, my personal experience with many projects tells me that the soft version I used is correct. I can recall many examples of how improper framing of the problem or improper conceptual design, including not only the technical aspects, led to costly rework and even projects that failed altogether. Further, if we phrase the IISP differently, we can bring to bear on the importance of design to project quality and success many undiscovered studies on project or system failures to support the argument. This however is beyond the scope of this editorial.

(7) Suppose you wanted to continue research on the IISP, what would you do with the literature study?

This question leads to the next sections.

\section{When is the time to do literature review}

I did not pick the exercise topic randomly. It has implication for literature review. Literature search should be done carefully before embarking on a study. Unfortunately, from my experience as an editor, it looks like many are done when the paper is done and authors realize that they must go back and do it properly; some also revise it after receiving reviewers' comments on their submission. Part of the problem is the drift in research topic during research, making the initial literature review less relevant and sometimes in part it relates to poor practice. Whatever the reason, at this final stage of writing the paper, it is much more complicated as the goal is to prove the point of the paper or to provide the rationale for the study and not to understand the state of the art. This is why negative information is hardly sought or mentioned. This is why no serious attempt exists to understand the literature fully because it might make the study redundant.

PSI framework clearly tells us we need periodic reflection. We need to constantly check the literature to scan for new insight. For example, in relation to the IISP, the related data we have is based on studies executed many years ago. Since then, manufacturing changed dramatically, design practices changed; we are presently undergoing another major revolution with additive manufacturing; our products are more complex and multidisciplinary including software that has no manufacturing cost; shouldn't we update the literature with new studies? If we do it periodically, we may need to change the research question or abandon it. This is similar to studying competitors, the market and, new technologies when we develop products to see if the initial product proposition is still viable.

Updating the literature should be easier than the initial study. If we did it properly, we are already familiar with the journals that publish these studies, the leading authors and research centers, the important conferences, and the main papers. Consequently, tracking new information is less difficult than initially. Another important point that can ease updating literature review is doing it properly with a framework that abstracts from the language of each reference and topic to create something new and revealing about the literature; more about it in Sect. 6.

\section{Can referencing fail?}

There could be many ways in which a reference we used is not doing the task. For example, a reference may claim something but its study is poor and does not really warrant the claim. Consequently, referencing should be done after reading the whole paper and not just its abstract, introduction or conclusions. Sounds trivial? I hope so.

Referencing may fail when we seek support for a claim and not arrive without preconceptions ready to find supporting and contradicting evidence; recall the IISP case above. Mentioning a reference because it also makes the claim but has no support is not helpful. Sometimes a study has many sources of information. The study synthesizes them into a coherent conclusion. Referencing part of the information without its overall context should be done very carefully not to distort its meaning. This is not an exhaustive list of referencing failures; the goal of this section is to keep in mind that anything we do including referencing may fail.

There are additional failures that come with failed referencing that we usually ignore. We may assume that an open question has been addressed by a reference; we may give credit to a reference that does not deserve it and subsequently, others may need to deal with refuting it; and we may not give credit to whomsoever it is due.

\section{References and frameworks}

One of the important topics in literature review is creating a summary of the state of the art beyond the idiosyncratic language that each study uses, in a way that readers could understand it as a whole. 
(8) Pick randomly 5 papers and reflect if their literature review goes beyond mentioning what each reference has done.

In creating the holistic view or model of the literature, new terms may be needed and they should be clearly defined. Sometimes it is instrumental to present the framework as a table, as a graphic image of influences, or as an annotated bibliography (see, Reich 1994, for an example) as many fields such as History and others do.

Let me give two examples. The PSI framework is one such example of a table format (Reich and Subrahmanian 2015, 2017). It allows taking data from different design situations, structure it into levels and the questions it answers, a $3 \times 3$ matrix, and use it to predict the success or failure of the design. Combining Tables 1, 2 and 3 while changing the 3 rd to refer to referencing practice, we get the complete matrix that can be used to explain the practice of referencing (Table 4). The top level was agreed upon in several meetings at ICED17. This editorial is part of the 2 nd level; it is a reflection on the state of referencing in the discipline in an attempt to take the vision and improve referencing practice. The value of a framework is its ability to abstract from different studies and present common terminology and relationships that others could understand and use. It is clear that if we do not engage in frequent discussion on this referencing subject, no change will be observed. It is clear that if a growing part of the community does not adhere to the vision, it will not care about improving its referencing practice.
Another example of capturing a framework is by a diagram. Consider the topic of modularity. Looking at many papers on the subject, some authors take it for granted that modularity is good. They advocate for it and sometimes proceed with developing methods to support modularity.

In a recent paper, Engel et al. (2016) summarize a long study designed to resolve a conflict in the concept of modularity: modularity is good to address future changes but may be expensive for the present. Deciding whether to modularize or not is non-trivial. Sifting through extensive literature, a simple model was used to summarize it, see Fig. 1. Without going into the specific language we see two strands of influences in the figure where the number of modules may increase or decrease the value of architectural adaptability. This could now be a basis for developing a method that will determine when to modularize by resolving in each case which strand is more important.

(9) Take one of your present studies and see how you can transform its literature survey into a framework.

\section{Checklist or guiding questions}

The following is a useful checklist or guiding questions when conducting a literature review or designing references:

Table 4 The PSI matric of referencing

\begin{tabular}{lllc}
\hline Nature of problem & What & Who \\
\hline 1 & Strategic vision & We need much better quality referencing & $\begin{array}{c}\text { Self-reflective research- } \\
\text { ers involved in editorial } \\
\text { practices } \\
2\end{array}$ \\
Implementation & Designing quality and acceptable referencing & $\begin{array}{c}\text { Fe, reviewers, authors, } \\
\text { others to be determined }\end{array}$ & $\begin{array}{c}\text { Editorial and community } \\
\text { process to be deter- } \\
\text { mined }\end{array}$ \\
Design & Designing a reference & Authors
\end{tabular}

Fig. 1 Conceptual framework summarizing two strands of theorized relationships between modularity and adaptability (from Engel et al. 2016)

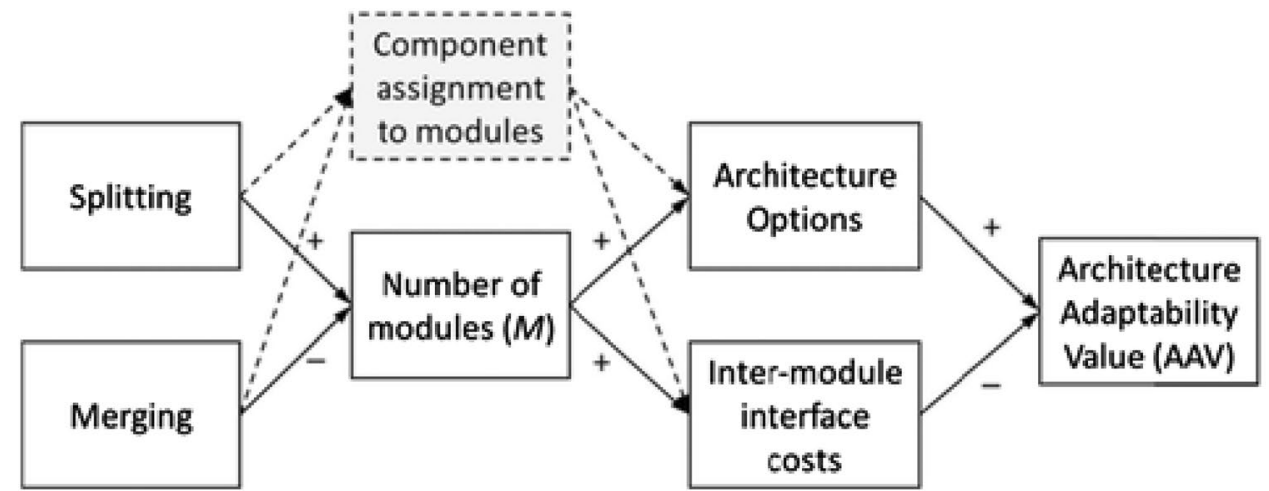


1. Are you attempting a literature review because you are starting a research project?

2. Did you read the reference you intend to cite?

3. Does the reference provide solid evidence or support?

4. Is there contradicting information to the claim you are attempting?

5. Are you citing a conference paper? If so, check whether there is a more recent journal publication. If so, start the checklist again with this reference in mind.

6. Make sure you explicitly classify the nature of references (see question (4) above). Consider stating this in the text.

7. Are you using the most credible source (not necessary one that has been referred to extensively)?

8. Did you create a framework to organize your literature?

9. Can you use the framework to clearly identify the gap in knowledge that you propose to study?

You will need to extend this list to make it valuable as you gain more experience or become more conscious about literature review. Please share it with colleagues. It is part of the community effort to improve this practice.

\section{References and academic culture}

In all cases, citing a reference adds to its prestige, whether the citation criticizes the reference or not. If we wanted to discount a study, stating it is badly executed or that its conclusions are wrong, we will still increase its prestige! With this type of attribution, we are reminded of the time when Facebook had only "like" button. But Facebook moved away from this allowing other ways of reaction, shouldn't we find a way to allow more elaborate reactions to references than counting citations? More seriously, it is rare to find criticism of studies in our discipline. This gives the wrong impression that everything that is published is of good quality and its conclusions valid. It is difficult to make progress in such practice.

We should refer to papers not only for their stated topic conclusions. Some papers provide an important methodological breakthrough in their study design, data collection or analysis; some papers conduct innovative literature search. If we learn from a study and use it, we should refer to it. I am suggesting that this is an ethical issue.

(10) Why, and in which circumstance would you consider citing this editorial?

I am giving you some potential answers but please exercise your own judgement.
- When you wish to present an example of PSI and how it can be used to derive value in an unconventional setting.

- When you wish to demonstrate that our discipline needs more discipline.

- When you wish to show that even simple concepts, we thought are unquestionable, such as a reference, occasionally require new elaboration.

\section{Epilogue}

The currency of academia is knowledge expressed in a variety of media, in particular, papers. Part of our work is building upon others work and our social and ethical culture requires us to make proper reference in such cases. The goal of this editorial is to create awareness to the subject, raise some important topics that can be observed from an editor's viewpoint and make it easier for authors, reviewers and editors to read papers since in the future, their literature study would be much better.

To encourage a debate in the community I invite responses and comments to the editorial and may collate them and publish it in the journal.

(11) Go over the editorial and think where would you consider I should have included additional references because my point was not supported?

(12) Some references in this editorial are good and some may be less-try to identify.

Acknowledgements Thanks to Eswaran Subrahmanian for his comments on a draft of this editorial.

\section{References}

Barabási AL (2009) Scale-free networks: a decade and beyond. Science 325(5939):412-413

Barton JA, Love DM, Taylor GD (2001) Design determines 70\% of cost? A review of implication for design, Journal of Engineering Design 12(1):47-58

Bragança L, Vieira SM, Andrade JB (2014) Early stage design decisions: the way to achieve sustainable buildings at lower costs. Sci World J 2014, Article ID 365364

Corbett J (1986) Design for economic manufacture. Annu CIRP 35:93-98

Engel A, Browning TR, Reich Y (2016) Designing products for adaptability: insights from four industrial cases. Decis Sci. doi:10.1111/ deci. 12254

Frey DD, Herder PM, Wijnia Y, Subramanian E, Katsikopoulos KV, and Clausing DP (2009) An evaluation of the Pugh controlled convergence method. Res Eng Des 20:41-58

Frey D, Herder P, Wijnia Y, Katsikopoulos K, de Neufville R, Oye K, Subrahmanian E, and Clausing D (2010) Research in engineering 
design: the role of mathematical theory and empirical evidence. Res Eng Des 21(3):145-151

Gairola A (1981) Montagegerechtes Konstruieren (Dissertation). Darmstadt, TU

Hatchuel A, Weil B (2003) A new approach to innovative design: an introduction to C-K theory. In: ICED'03, August 2003, Stockholm, Sweden

Hatchuel A, Weil B (2009) C-K design theory: an advanced formulation. Res Eng Des 19(4):181-192

Hazelrigg GA (2010) The Pugh Controlled Convergence method: model-based evaluation and implications for design theory. Res Eng Des 21(3). doi:10.1007/s00163-010-0087-0

Hsu W, Woon IM (1998) Current research in the conceptual design of mechanical products. Comput Aided Des 30(5):377-389

Kohler N, Moffatt S (2003) Life-cycle analysis of the built environment, United Nations Environment Programme Division of Technology, Industry and Economics Publication. UNEP Ind Environ 26(2-3):17-21

Laird JE, Newell A, Rosenbloom PS (1987) Soar: an architecture for general intelligence. Artif Intell 33(1):1-64

Le Masson P, Weil B, Hatchuel A (2017) Design theory-methods and organization for innovation. Springer, Cham, Switzerland

Lotter B (1986) Manufacturing assembly handbook, 2nd edn. Butterworths, Boston

Mileham AR, Currie GC, Miles AW, Bradford DT (1993) A parametric approach to cost estimating at the conceptual stage of design. Journal of engineering design 4(2):117-125

Newell A (1973) You can't play 20 questions with nature and win: projective comments on the papers of this symposium. In: Chase WG (ed) Visual Information Processing. Academic, New York

Pahl G, Beitz W (1996) Engineering design: a systematic approach, 2nd edn. Springer, London

Redner S (1998) How popular is your paper? An empirical study of the citation distribution. Eur Phys J B Condens Matter Complex Syst 4(2):131-134

Reich Y (1994) Annotated bibliography on research methodologies. AI EDAM 8(4):355-366
Reich Y (2008) Preventing breakthroughs from breakdowns. In: Proceedings of the 9th biennial ASME conference on engineering systems design and analysis ESDA 2008, Haifa

Reich Y (2010a) My method is better! Editorial. Res Eng Des 21(3):137-142

Reich Y (2010b) Design religions, DESIGN 2010, Dubrovnik. Keynote lecture. Video presentation in the Alta Scuola Politecnica (ASP)—Design Methods Program, Belgirate, Italy, May 2012. https://www.youtube.com/watch? $\mathrm{v}=1 \mathrm{r} 3 \mathrm{NEJZHyOA}$

Reich Y (2017) The principle of reflexive practice. Des Sci. doi:10.1017/dsj.2017.3

Reich Y, Subrahmanian E (2015) Designing PSI: an introduction to the PSI framework. In: The proceedings international conference on engineering design, ICED'15, Milan

Reich Y, Subrahmanian E (2017) The PSI matrix - a framework and a theory of design. In: ICED'17, Vancouver

Saravi M, Newnes L, Mileham AR, Goh YM (2008) Estimating cost at the conceptual design stage to optimize design in terms of performance and cost. In: Curran R, Chou SY, Trappey A (eds) Collaborative product and service life cycle management for a sustainable world. Advanced concurrent engineering. Springer, London

Simon HA (1996) The sciences of the artificial, 3rd edn. MIT press, Cambridge

Symon RJ, Dangerfield KJ (1980) Application of design to cost in engineering and manufacturing. In: NATO AGARD Lecture Series No. 107, The application of design to cost and life cycle cost to aircraft engines (Saint Louis, France, 12-13 May, London, UD 15-16), pp 7.1-7.17

Ullman DG (2003) The mechanical design process. McGraw-Hill, New York, NY

Ulrich KT, Pearson SA (1993) Does product design really determine $80 \%$ of manufacturing cost? Working Paper WP\#3601-93. Alfred P. Sloan School of Management, MIT, Cambridge

Wang MY, Yu G, Yu DR (2010) The scale-free model for citation network. In: Intelligent computing and intelligent systems (ICIS), 2010 IEEE international conference, vol 1. IEEE, pp 773-776 